\title{
CARA CEPAT UNTUK MENDETEKSI KEBERADAAN WAJAH PADA CITRA YANG MEMPUNYAI BACKGROUND KOMPLEKS MENGGUNAKAN MODEL WARNA YCbCr DAN HSV
}

\author{
Nurul Hidayat ${ }^{1}$, Muh. Arif Rahman ${ }^{2}$ \\ ${ }^{1,2}$ Fakultas Ilmu Komputer Universitas Brawijaya Malang \\ Email: ${ }^{1}$ ntayadih@ub.ac.id, ${ }^{2}$ __arif@ub.ac.id
}

(Naskah masuk: 11 Juni 2015, diterima untuk diterbitkan: 22 Juli 2015)

\begin{abstract}
Abstrak
Pendeteksi wajah dari sebuah citra baik berupa gambar diam maupun bergerak merupakan topik penting dan menarik saat ini. Proses deteksi keberadaan wajah ini menjadi dasar dari proses pengenalan wajah yang mempunyai banyak implementasi baik pada bidang keamanan maupun sosial media. Tujuan dari proses deteksi wajah adalah untuk mengetahui apakah ada wajah dari suatu citra, kemudian menemukan letak keberadaan wajah. Pendeteksian wajah adalah tahapan penting dari aplikasi yang memanfaatkan keberadaan wajah pada suatu citra. Implementasinya cukup banyak terutama di bidang biometri keamanan dan sosial media. Riset ini mengusulkan deteksi wajah menggunakan 3 tahapan umum yaitu segmentasi warna kulit manusia, binarisasi dan penentuan region garis serta deteksi wajah menggunakan ruang warna $\mathrm{YCbCr}$ dan $\mathrm{HSV}$. Dalam penelitian ini dilakukan deteksi wajah pada 10 citra yang memiliki background yang kompleks. Pendeksian lokasi wajah didasarkan pada temuan hole mata yang simetris. Wajah yang terlalu kecil membuat keberadaan mata hanya terdeteksi sebelah sehingga mengakibatkan wajah tidak terdeteksi. Hasil evaluasi didapatkan tingkat akurasi ratarata deteksi wajah mencapai $83,4 \%$ dengan kecepatan rata-rata 6530 piksel/detik.
\end{abstract}

Kata kunci: Deteksi Wajah, Biometri, Segmentasi, YCbCr, HSV, Region Garis

\begin{abstract}
Face detection of an image either still or moving image is an important and interesting topic today. Face detection process where it became the basis of face recognition process that has many implementations, both in the field of security and social media. The aim of the face detection process is to determine whether there is a face from an image, and then locate the whereabouts of the face. Face detection of an image, either a statis or moving image Face detection is an important phase in application system to utilize face location in an image. It is so many implementations such asspecially for security and sociality biometrics field. Here, it suggest to detect the face location with 3 steps, skin human color segmentation step, binnerization step, and locate line region then detection step of face location by $\mathrm{YCbCr}$ and $\mathrm{HSV}$ color region. Here, ten images which have a complex background are implemented. To detect face location based on finding symetris of eyes hole. The faces which are too small made the eyes locations are only detected a half, so the face can't detect. The evaluation result obtained average of accuration of face detection $83,4 \%$ with average time to detect 6530 pixel/second.
\end{abstract}

Keywords: Face detection, Biometry, Segmentation, $\mathrm{YCbCr}$, HSV, Line Region

\section{PENDAhuluan}

Pendeteksi wajah dari sebuah citra baik berupa gambar diam maupun bergerak merupakan topik penting dan menarik saat ini. Proses deteksi keberadaan wajah ini menjadi dasar dari proses pengenalan wajah yang mempunyai banyak implementasi baik pada bidang keamanan maupun sosial media. Tujuan dari proses deteksi wajah adalah untuk mengetahui apakah ada wajah dari suatu citra dan atau menemukan letak keberadaan wajah. Pada citra yang kompleks, proses ini menjadi sulit karena dalam suatu citra yang kompleks, wajah bisa ada di posisi manapun, ukurannya bisa bervariasi dan jumlahnya lebih dari satu. Secara umum, metode deteksi wajah awalnya dikembangkan berdasarkan pengetahuan, karakteristik wajah dan template matching. Namun, kelemahan metode tersebut adalah sensitif terhadap cahaya, akurasinya rendah dan diperlukan transformasi ukuran wajah yang dideteksi (Chen Aiping et al., 2010). Metode pengetahuan didasarkan pada pengetahuan manusia akan geometri wajah. Sejumlah metode telah dikembangkan berdasarkan metode pengetahuan (Kouzani et al., 1997). Metode karakteristik dikembangkan karena sebuah wajah mempunyai sejumlah feature unik seperti mata, hidung, mulut, rambut (Rita et al., 2010). Pada metode template matching, sebuah wajah dibuat sebagai model atau template yang dipelajari dari sejumlah database wajah. Sejumlah metode popular telah digunakan oleh periset, diantaranya adalah 
PCA, Eigenface, LDA, SVM, Hidden Markov Model (Wang and Yang, 2008).

Secara umum, agar deteksi keberadaan wajah pada citra dapat dilakukan maka diperlukan 3 tahap yaitu deteksi piksel sebagai warna kulit, segmentasi warna kulit dan pencocokan obyek wajah. Sejumlah metode deteksi warna kulit manusia telah dikembangkan (Zhanwu Xu and Miaoliang Zhu, 0-0 $0)$. Diantaranya adalah metode sederhana dan cepat (Rita et al., 2010; Yuanyuan Liu et al., 2009), yaitu dengan cara citra RGB dikonversi ke ruang warna HSV dan $\mathrm{YCbCr}$ dan kemudian dilakukan deteksi menggunakan kombinasi criteria range dari 2 warna tersebut. Cara cepat lainnya dilakukan dengan cara menyusun vektor elemen warna $\mathrm{HSV}$ dan $\mathrm{YCbCr}$, kemudian dicari matrik kovariannya (Muh. Arif Rahman, 2014). Dan selanjutnya semua piksel dideteksi sebagai warna kulit. Tahapan berikutnya adalah segmentasi warna kulit. Tujuan segmentasi adalah mencari

daerah warna kulit dan menghilangkan area yang bukan warna kulit. Terdapat sejumlah metode diantaranya adalah dengan menggunakan Texture Feature

Extraction dan Clustering $\mathrm{K}$-Mean kemudian menggabungkannya dengan metode Gaussian Mixture Model Classifier (Pan $\mathrm{Ng}$ and Chi-Man Pun, 2011), Bayesian Decision Theory berbasis pembelajaran database warna kulit (Son Lam Phung et al., 2003), Support Vector Machine (SVM) dan Region Segmentation (Han et al., 2009), model Markov digunakan untuk mengatasi variasi iluminasi (Sigal et al. 2000), Bayesian Model dan sifat-sifat homogen warna kulit (Phung et al., 2003).

Tahapan terakhir sesudah segmentasi warna kulit adalah deteksi keberadaan wajah. Terdapat sejumlah pendekatan dari yang rumit (memerlukan komputasi yang cukup banyak) hingga yang sederhana. Diantara metode yang sederhana adalah deteksi wajah berbasis piksel tepi warna kulit dan didiagnosa menggunakan Fuzzy Logic (Pham The Bao et al., 2005), deteksi keberadaan posisi mata dan sifat simetrinya menggunakan SVM (Wei Wang et al., 2002), algoritma adabost (Lijing Zhang and Yingli Liang, 2010), koefisien DCT menggunakan citra jpeg resolusi rendah (Tian Qing and Zhao Shiwei, 2012) dan metode Haar Classifier pada citra yang mempunyai variasi iluminasi (Goel and Agarwal, 2012).

Penelitian-penelitian pada deteksi wajah secara umum menginformasikan bahwa cara yang digunakan termasuk cepat dan hasilnya baik pada citra dengan keberadaan tunggal maupun lebih dari satu dan juga adaptif pada berbagai iluminasi namun tidak pada citra yang mempunyai background kompleks. Background kompleks pada citra merupakan elemen non wajah yang mempunyai warna seperti warna kulit manusia dan elemenelemen non wajah seperti tangan. kaki dll.

\section{TINJAUAN PUSTAKA}

\subsection{Ruang Warna Dan Model Warna Kulit Manusia}

Ruang warna popular pada pemrosesan citra digital adalah RGB. Namun jika untuk pengenalan kulit ruang warna RGB hasilnya sering kali tidak baik maka yang sering digunakan adalah ruang warna persepsional yaitu ruang warna HSV dan YCbCr. Ruang warna HSV diperoleh dengan menggunakan konversi RGB sbb :

Nilai $R, G$ dan $B$ dibagi dengan diperoleh range nilai dari 0 hingga 1 dinyatakan pada persamaan (1)

$R^{\prime}=\frac{R}{255}, G^{\prime}=\frac{G}{225}, B^{\prime}=\frac{B}{225}$

Kemudian dihitung nilai maks minimumnya dengan menggunakan persamaan (2).

$$
\begin{gathered}
C \max =\max \left(R^{\prime}, G^{\prime}, B^{\prime}\right) \\
C \min =\min \left(R^{\prime}, G^{\prime}, B^{\prime}\right) \\
\Delta=C \max -C \min
\end{gathered}
$$

Ruang warna HSV mempunyai elemen Hue (H), Saturation (H) dan Value (V). Adapun konversinya dinyatakan dengan persamaan (3), (4) dan (5).

$$
\begin{aligned}
& H=\left\{\begin{array}{l}
60^{\circ} \times\left(\frac{G^{\prime}-B^{\prime}}{\Delta} \bmod 6, C \max =R^{\prime}\right. \\
60^{\circ} \times\left(\frac{B^{\prime}-R^{\prime}}{\Delta}+2, C \max =G^{\prime}\right. \\
60^{\circ} \times\left(\frac{R^{\prime}-G^{\prime}}{\Delta}+4, C \max =B^{\prime}\right.
\end{array}\right. \\
& S= \begin{cases}0, & \Delta=0 \\
\frac{\Delta}{C \max }, & \Delta<>0\end{cases}
\end{aligned}
$$

$V=C \max$

Sedangkan range nilai yang diketahui untuk klasifikasi kulit manusia dinyatakan dalam pertaksamaan (6).

$$
\begin{aligned}
V \geq 40 \text { dan } 0.2 & <S<0.6 \text { dan } 0<H \\
& <25 \text { dan } 335<H \\
& <360
\end{aligned}
$$

Ruang warna YCbCr diperoleh dengan menggunakan konversi RGB pada persamaan (7).

$$
\begin{gathered}
Y=0.299 R+0.587 G+0.114 B \\
C b=B-Y \\
C r=R-Y
\end{gathered}
$$

Sedangkan ruang warna kulit manusia didefinisikan pada pertaksamaan (8).

$77 \leq C b \leq 127$ dan $133 \leq C r \leq 173$ 


\subsection{Enhancement Citra}

Enhancement citra adalah peningkatan kualitas citra sesuai dengan keinginan pengguna. Dalam hal ini adalah untuk menaikkan proporsi pengenalan warna kulit manusia. Rumusan enhancement citra telah dibuat oleh Deepak (Ghimire, Deepak; and Lee, Joonwhoan, 2013) yang terdiri atas 2 tahap yaitu:

a. Enhancement pada elemen luminance dinyatakan pada persamaan (9).

$V_{L E}=\frac{V_{I}^{(0.75 z+0.25)}+0.4(1-z)\left(1-V_{I}\right)+V_{I}^{(2-z)}}{2}$

Dimana nilai $\mathrm{z}$ dinyatakan pada persamaan (10).

$$
z=\left\{\begin{aligned}
0, & \text { for } L \\
\frac{L-50}{100}, \text { for } 50 & <L \leq 150 \\
1, \text { for } L & >150
\end{aligned}\right.
$$

Nilai Vi adalah nilai $\mathrm{Cb}$ atau $\mathrm{Cr}$ pada ruang warna $\mathrm{YCbCr}$ dan $\mathrm{L}$ menyatakan nilai luminance.

b. Enhancement pada elemen kontras

Enhancement melalui nilai kontras dilakukan dengan operasi konvolusi fungsi Gauss $G(x, y)$ yang diterapkan pada input warna HSV yaitu $\mathrm{V}(\mathrm{x}, \mathrm{y})$. Adapun rumusannya dinyatakan pada persamaan (11).

$$
V_{C O N}(x, y)=V_{i}(x, y) \otimes G(x, y)
$$

$V_{\text {con }}(x, y)$ menyatakan nilai hasil konvolusi, $V_{i}(x, y)$ nilai sebelum konvolusi dan operator $\otimes$ merupakan matrik $m \times m$ gaus $G(x, y)$.

\subsection{Segmentasi Menggunakan Metode Connected Labeling}

Sebuah path dari piksel $\mathrm{p}$ yang mempunyai koordinat $(\mathrm{x}, \mathrm{y})$ ke piksel $\mathrm{q}(\mathrm{s}, \mathrm{t})$ adalah barisan piksel yang berbeda yaitu $\left(x_{o}, y_{o}\right),\left(x_{1}, y_{1}\right),\left(x_{2}, y_{2}\right) \ldots\left(x_{n}, y_{n}\right) \quad$ dimana $\left(x_{o}, y_{o}\right)=(x, y)$ dan $\left(x_{n}, y_{n}\right)=(s, t)$. Dalam hal ini dikatakan bahwa $(x, y)$ dan $(s, t)$ adalah connected. Jika $(x, y)=(s, t)$ maka disebut path tertutup dan $n$ adalah panjang dari path. Pada Gambar 1 disajikan 4-connected, 8-connected dan m-connected,

$$
\begin{aligned}
& 0 \quad 1 \cdots 1 \\
& 010 \\
& 0 \quad 1 \cdots 1 \\
& 0 \text { - } 0 \\
& \begin{array}{lll}
0 & 0 & 1
\end{array} \\
& 0 \quad 0 * 1 \\
& \begin{array}{llll}
0 & 1 \cdots & 1 \\
0 & 1 & 0 \\
0 & 0 & \ddots & 1
\end{array}
\end{aligned}
$$

Gambar 1. Macam-macam Connected

2 piksel $\mathrm{p}$ dan $\mathrm{q}$ adalah $\mathrm{m}$-connected jika (i) q berada pada $N_{4}(p)$ atau (ii) q berada pada $N_{D}(p)$ dan $N_{4}(p) \cap N_{4}(q)$ adalah kosong. Dengan demikian jika $S$ adalah subset dari piksel dalam suatu citra, 2 piksel p dan q disebut connected jika di S terdapat path yang menghubungkannya. Maka sembarang $p$ di S disebut komponen connected.

\section{LINGKUNGAN UJI COBA, HASIL DAN PEMBAHASAN}

Data yang digunakan adalah data citra koleksi pribadi yang memuat wajah dan mempunyai background yang kompleks disajikan pada Tabel 1.

Tabel 1. Daftar Citra Penelitian

\begin{tabular}{clc}
\hline No & $\begin{array}{c}\text { Nama dan Ukuran } \\
\text { Citra }\end{array}$ & $\begin{array}{c}\text { Jumlah } \\
\text { Wajah }\end{array}$ \\
\hline 1 & Citra01(298,478) & 3 \\
\hline 2 & Citra02(234,453) & 6 \\
\hline 3 & Citra03 $(419,269)$ & 1 \\
\hline 4 & Citra04 $(283,389)$ & 1 \\
\hline 5 & Citra05 $(332,309)$ & $3(2.10)$ \\
\hline 6 & Citra06 $(288,350)$ & 4 \\
\hline 7 & Citra07 $(208,491)$ & 1 \\
\hline 8 & Citra08 $(335,541)$ & 3 \\
\hline 9 & Citra09 $(277,400)$ & 5 \\
\hline 10 & Citra10 $(487,367)$ & 1 \\
\hline
\end{tabular}

Proses eliminasi non wajah dan hasil pendeksian jumlah wajah yang dapat dikenali oleh sistem pada Citra01 dan Citra02 disajikan di Tabel 2 dan Tabel 3. Sedangkan proses eliminasi non wajah dan dan hasil pendeksian jumlah wajah yang dapat dikenali oleh sistem dengan menggunakan data uji sebanyak 10 citra disajikan pada Tabel 4.

Tabel 2. Hasil Pendeksian Wajah Citra 01

\begin{tabular}{lll} 
Nama \\
Citra \\
Citra Asli \\
Deteksi \\
Wajah \\
Wajah \\
\hline Jml Wajah \\
Dikn Wajah
\end{tabular}


Tabel 3. Hasil Pendeksian Wajah Citra 02

\begin{tabular}{lll}
\hline Nama & Citra02 \\
Citra & \\
Citra Asli & & \\
Eliminasi \\
Non \\
Wajah
\end{tabular}

Tabel 4. Citra Hasil Pendeksian Wajah

\begin{tabular}{lcc}
\hline Nama Citra & $\begin{array}{c}\text { Jml } \\
\text { Wajah }\end{array}$ & $\begin{array}{c}\text { Jml Wajah } \\
\text { Dikenali }\end{array}$ \\
\hline Citra 01 & 3 & 3 \\
\hline Citra 02 & 6 & 4 \\
\hline Citra 03 & 1 & 1 \\
\hline Citra 04 & 1 & 1 \\
\hline Citra 05 & 3 & 2 \\
\hline Citra 064 & 4 & 2 \\
\hline Citra 07 & 1 & 1 \\
\hline Citra 08 & 3 & 3 \\
\hline Citra 09 & 5 & 3 \\
\hline Citra 10 & 1 & 1 \\
\hline
\end{tabular}

Pada Pengukuran yang dilakukan dengan mencari prosentasi jumlah wajah yang dikenali pada citra dari jumlah wajah sebenarnya dan waktu yang diperlukan dalam proses deteksi. Tingkat akurasi dilakukan utk mengukur tingkat keberhasilan metode yang digunakan, sedangkan pengukuran waktu dilakukan untuk mendapatkan kecepatan proses deteksi. Hasil implementasi didapatkan tingkat akurasi deteksi wajah dan waktu proses ditunjukkan pada Tabel 3.

Pada Tabel 5, Citra02, Citra05, Citra06 dan Citra09 terdapat wajah yg tidak terdeteksi. Pada Citra02 dan Citra09 terdapat ukuran wajah yang terlalu kecil sehingga sistem tidak mampu mendeteksi. Sedangkan pada Citra05 dan Citra06 terdapat wajah miring membuat sistem gagal mendeteksi keberadaan simetris hole mata. Namun demikian sistem berhasil mendeteksi keberadaan wajah dengan rata-rata tingkat akurasi sebesar $84 \%$ dengan kecepatan rata-rata 6530 piksel/detik.
Tabel 5. Tingkat Akurasi Deteksi Wajah dan Kecepatan Proses

\begin{tabular}{llll}
\hline $\begin{array}{c}\text { Nama } \\
\text { Citra }\end{array}$ & $\begin{array}{c}\text { \% } \\
\text { Terde } \\
\text { teksi }\end{array}$ & $\begin{array}{c}\text { Waktu } \\
\text { Proses } \\
\text { (Detik) }\end{array}$ & $\begin{array}{c}\text { Kecepatan } \\
\text { (perdetik) }\end{array}$ \\
\hline Citra 01 & 100,0 & 22 & 6475 \\
\hline Citra 02 & 66,7 & 16 & 6625 \\
\hline Citra 03 & 100,0 & 17 & 6630 \\
\hline Citra 04 & 100,0 & 17 & 6476 \\
\hline Citra 05 & 66,7 & 15 & 6839 \\
\hline Citra 06 & 50,0 & 16 & 6300 \\
\hline Citra 07 & 100,0 & 15 & 6809 \\
\hline Citra 08 & 100,0 & 29 & 6249 \\
\hline Citra 09 & 60,0 & 17 & 6518 \\
\hline Citra 10 & 100,0 & 28 & 6383 \\
\hline & $\mathbf{8 4 , 3}$ & $\mathbf{1 9 , 2}$ & $\mathbf{6 5 3 0}$ \\
\hline
\end{tabular}

\section{KESIMPULAN DAN SARAN}

\section{Kesimpulan :}

Dalam penelitian ini telah dilakukan deteksi wajah pada 10 citra yang memiliki background kompleks dengan menggunakan model warna HSV dan YCbCr. Pendeksian lokasi wajah didasarkan pada temuan hole mata yang simetris. Wajah yang terlalu kecil membuat keberadaan mata hanya terdeteksi sebelah sehingga mengakibatkan wajah tidak terdeteksi.

Hasil evaluasi pada pengujian 10 citra berlatar belakang kompleks, tingkat akurasi rata-rata deteksi wajah mencapai $83,4 \%$ dengan kecepatan rata-rata $6530 \mathrm{piksel} / \mathrm{detik}$.

\section{Saran :}

Untuk mengurangi kegagalan pada deteksi mata pada citra yang mengandung wajah-wajah berukuran kecil, disarankan untuk dilakukan scaling setelah proses segmentasi.

\section{DAFTAR PUSTAKA}

Chen Aiping, Pan Lian, Tong Yaobin, Ning Ning, 2010. Face Detection Technology Based on Skin Color Segmentation and Template Matching. Educ. Technol. Comput. Sci. ETCS 2010 Second Int. Workshop On 2, 708-711.

Ghimire, Deepak ; Lee, Joonwhoan, 2013. A Robust Face Detection Method Based on Skin Color and Edges. J. Inf. Process. Syst. 9, 141-156.

Goel, P., Agarwal, S., 2012. An Illumination Invariant Robust and Fast Face Detection, Feature Extraction Based Face Recognition System. Comput. Commun. Technol. ICCCT 2012 Third Int. Conf. On 110-115. 
Han, J., Awad, G., Sutherland, A., 2009. Automatic skin segmentation and tracking in sign language recognition. Comput. Vis. IET 3, 24-35.

Kouzani, A.Z., He, F., Sammut, K., 1997. Commonsense knowledge-based face detection. Intell. Eng. Syst. 1997 INES 97 Proc. 1997 IEEE Int. Conf. On 215-220.

Lijing Zhang, Yingli Liang, 2010. A fast method of face detection in video images. Adv. Comput. Control ICACC 2010 2nd Int. Conf. On 4, 490-494.

Muh. Arif Rahman, 2014. Deteksi Warna Kulit Manusia Berbasis Piksel Menggunakan Ruang Warna HSV Dan YCbCr. Presented at the KNSI 2014, Makasar Indonesia.

Pan Ng, Chi-Man Pun, 2011. Skin Color Segmentation by Texture Feature Extraction and K-mean Clustering. Comput. Intell. Commun. Syst. Netw. CICSyN 2011 Third Int. Conf. On 213218.

Rita, V., Anupam Agrawal, Shanu Sharma, 2010. A Robust \& Fast Face Detection System. ACEEE Int J Signal Image Process., 03 01, 17-22.

Sigal, L., Sclaroff, S., Athitsos, V., 2000. Estimation and prediction of evolving color distributions for skin segmentation under varying illumination. Comput. Vis. Pattern Recognit. 2000 Proc. IEEE Conf. On 2, 152-159 vol.2.

Son Lam Phung, Chai, D., Bouzerdoum, A., 2003. Adaptive skin segmentation in color images. Multimed. Expo 2003 ICME 03 Proc. 2003 Int. Conf. On 3, III-173-6 vol.3.

Tian Qing, Zhao Shiwei, 2012. A fast face detection method for JPEG image. Signal Process. ICSP 2012 IEEE 11th Int. Conf. On 2, 899902.

Wang, J., Yang, H., 2008. Face Detection Based on Template Matching and 2DPCA Algorithm. Image Signal Process. 2008 CISP 08 Congr. On 4, 575-579.

Wei Wang, Yongsheng Gao, Siu Chueng Hui, Karhang Leung, 2002. A fast and robust algorithm for face detection and localization. Neural Inf. Process. 2002 ICONIP 02 Proc. 9th Int. Conf. On 4, 2118-2121 vol.4.

Yuanyuan Liu, Haibin Yu, Zhiwei He, Xueyi Ye, 2009. Fast Robust Face Detection under a Skin Color Model with Geometry Constraints. Comput. Intell. Secur. 2009 CIS 09 Int. Conf. On 2, 515-519.

Zhanwu Xu, Miaoliang Zhu, 0-0 0. Color-based skin detection: survey and evaluation. MultiMedia Model. Conf. Proc. 2006 12th Int. 10 pp. 